\title{
ANALISIS PENGARUH JARAK PEMASANGAN PVD TERHADAP DERAJAT KONSOLIDASI PADA KONSTRUKSI TIMBUNAN
}

\author{
Daniel Anderson Munthe, Roesyanto dan Rudi Iskandar \\ Universitas Sumatera Utara (USU) Medan, Indonesia \\ Email: 90hdecindonesia@gmail.com, roesyantos@yahoo.com dan \\ sipil.s2.usu@gmail.com
}

\begin{tabular}{l}
\hline INFO ARTIKEL \\
\hline Diterima \\
10 Februari 2021 \\
Direvisi \\
21 Februari 2021 \\
Disetujui \\
15 Maret 2021
\end{tabular}

\section{Keywords:}

preloading method, PVD, plaxis $2 D$, consolidation.

\section{ABSTRACK}

Preloading and vertical drainage methods are among the popular methods used to increase the strength of soft soil shear with the same or greater loading size than the load that will be carried by the soil both during the construction stage and after the construction phase is completed. While vertical drainage can speed up the consolidation process. Based on the development of vertical drainage is the use of PVD (Prefabricated Vertical Drain). PVD is installed to drain water that is dissipated due to the consolidation process. Based on the development of vertical drainage is the use of PVD (Prefabricated Vertical Drain). PVD is installed to drain water that is dissipated due to the consolidation process. This analysis aims to compare the results of a closer decline between analytical calculations and with 2D Plaxis modeling either without taking into account the effects of smear zones or by taking into account the effects of smear zones. As for the actual decrease that occurred in the field based on settlement plate-02 data is 1,637 meters. The time required in the consolidation process using Plaxis $2 \mathrm{D}$ modeling is good by taking into account the effect of smear zone longer than without taking into account the effect of smear zone.

\footnotetext{
ABSTRAK

Metode pembebanan awal (preloading) dan drainase vertikal adalah salah satu metode populer yang digunakan untuk meningkatkan kuat geser tanah lunak dengan besar pembebanan yang sama atau lebih daripada beban yang akan dipikul oleh tanah baik saat tahapan konstruksi maupun setelah tahapan konstruksi selesai. Sedangkan drainase vertikal dapat mempercepat proses konsolidasi. Berdasarkan perkembangan drainase vertikal adalah penggunaan PVD (Prefabricated Vertical Drain). PVD berfungsi untuk mengalirkan air yang terdisipasi akibat proses konsolidasi. Penelitian ini bertujuan untuk
} 
Kata Kunci:

metode preloading; PVD; plaxis 2D; konsolidasi membandingkan hasil penurunan yang lebih mendekati antara perhitungan analitis dan dengan pemodelan Plaxis 2D baik tanpa memperhitungkan efek smear zone maupun dengan memperhitungkan efek smear zone. Berdasarkan hasil analisis ini diperoleh untuk perhitungan derajat konsolidasi pemasangan PVD dengan jarak pemasangan 1 meter lebih cepat dibandingkan jarak 1,3 meter dan 1,5 meter dan juga hasil analisis ini diperoleh besar penurunan yang terjadi pada proses konsolidasi dengan pemodelan pada Plaxis 2D dengan memperhitungkan efek smear zone adalah 1,484 meter dan 1,76 meter tanpa memperhitungkan efek smear zone. Sedangkan untuk penurunan aktual yang terjadi dilapangan berdasarkan data Settlement Plate-02 adalah 1,637 meter. Waktu yang dibutuhkan dalam proses konsolidasi menggunakan pemodelan Plaxis 2D baik dengan memperhitungkan efek smear zone lebih lama dibandingkan tanpa memperhitungkan efek smear zone.

Coresponden Author

Email: 90hdecindonesia@gmail.com Artikel dengan akses terbuka dibawah lisensi

\section{Pendahuluan}

Masalah konsolidasi dalam konstruksi reklamasi merupakan hal yang penting untuk dianalisis, terlebih jika kondisi tanah eksisting merupakan tanah lunak yang memiliki lapisan yang dalam. Konsolidasi adalah suatu proses pengecilan volume secara perlahan pada tanah jenuh sempurna dengan permeabilitas rendah akibat pengaliran sebagian air pori. Proses tersebut berlangsung terus sampai kelebihan tegangan air pori yang disebabkan oleh kenaikan tegangan total telah hilang (Munthe, 2020). Salah satu teori yang umum digunakan untuk memprediksi penurunan dan waktu yang dibutuhkan adalah teori konsolidasi satu dimensi yang diperkenalkan oleh (Adnan, 2014) dimana deformasi dan arah aliran hanya terjadi pada satu arah yaitu pada arah vertikal.

Proses konsolidasi sempurna akan membutuhkan waktu yang lama jika prosesnya terjadi secara alami. Untuk mengatasi hal tersebut, metode pra pembebanan (preloading) dan drainase vertikal merupakan solusi yang tepat untuk mempercepat proses konsolidasi (Iskandar, 2018).

Preloading merupakan suatu metode perbaikan tanah dengan cara menempatkan timbunan pada lokasi yang akan distabilisasi dengan berat sekurang-kurang nya sama dengan berat struktur atau beban permanen di masa yang akan datang. Preloading menyebabkan percepatan precompression laju konsolidasi, mengurangi penurunan konsolidasi primer, dan menaikkan kekuatan geser lunak (Widhiarto et al., 2018) 
Selain preloading, penggunaan metode drainase vertikal dapat digunakan untuk mengalirkan air yang keluar akibat beban dari proses konsolidasi yang terjadi. Drainase vertikal adalah aliran air yang dibuat pada konstruksi timbunan dalam bentuk vertikal untuk mengalirkan air yang keluar akibat penambahan tegangan air pori yang terjadi saat proses preloading. Drainase vertikal hanya mempercepat konsolidasi primer saja, karena pengaliran air yang signifikan hanya terjadi pada saat konsolidasi primer. Selama tiga dekade, berbagai jenis drainase vertikal, termasuk sand drain, sand compaction piles, PVD, dan gravel piles telah dipelajari. (Aspara \& Fitriani, 2016) memperkenalkan drainase cetakan berbentuk pita (prefabricated band shape drain) dengan sebuah inti plastik beralur yang dibungkus dengan selubung filter terbuat dari kertas karton untuk perbaikan tanah. Fungsi utama saringan drainase vertikal adalah untuk memastikan partikel halus tidak lolos dan menyumbat saluran dalam inti (Susiazti et al., 2020). Menurut (Weber et al., 2010) drainase vertikal diklasifikasikan kedalam tiga tipe umum: sand drain, fabric-encased sand drains, dan pre-fabricated band drain.

Pada pemasangan PVD diasumsikan bahwa sifat-sifat tanah sekelilingnya tidak berubah. Tapi pada kenyataannya, pemasangan PVD sedikit mengganggu tanah, tergantung pada sensifitas tanahnya. PVD dimasukkan ke dalam tanah dengan menggunakan mandrel dan diujungnya diberikan sepatu. Akibat pemasangan ini, maka lapisan tanah yang ditusuk mandrel akan terganggu (Aradea, 2019). Gangguan yang terjadi tersebut disebut efek smear. Efek smear adalah berkurangnya nilai koefisien permeabilitas tanah arah radial $(\mathrm{kr})$ akibat proses peremasan (remoulding) selama pemasangan PVD (Iskandar, 2018). Untuk itu perlu dilakukan perhitungan derajat konsolidasi dengan memperhitungkan efek smear zone untuk mendapatkan hasil yang lebih akurat.

(Sumiati et al., 2018) telah melakukan analisis terkait pengaruh kedalaman PVD terhadap waktu penurunan pada proyek pembangunan PLTU II, Cirebon. Hasil analisis tersebut adalah semakin panjang PVD yang dipasang, maka semakin sedikit waktu yang dibutuhkan untuk mencapai derajat konsolidasi 90\%. Terkait pengaruh jarak pemasangan PVD, (Ady Noegroho, 2016) menghitung pengaruh jarak dan pola pemasangan PVD pada perbaikan tanah lempung lunak di proyek PLTU Riau. Berdasarkan hasil perhitungan disimpulkan bahwa pemasangan PVD yang optimal untuk mempercepat waktu konsolidasi adalah pola segitiga dengan jarak pemasangan 1,5 meter. (Yapriadi et al., 2020) juga melakukan analisis pada pengaplikasian PVD untuk stabilisasi tanah dasar pada proyek Jalur Ganda KA Gombong, Kebumen. Hasil analisis tersebut adalah perbaikan tanah untuk mencapai derajat konsolidasi 90\% menggunakan PVD berpola segitiga membutuhkan jarak pemasangan PVD 0,8 m dengan waktu tunggu 15 minggu.

Selain dengan perhitungan secara empiris, derajat konsolidasi juga dapat diprediksi menggunakan pemodelan Plaxis 2D seperti yang telah dilakukan oleh (Zhang et al., 2018) sehingga analisis dapat dilakukan secara dua dimensi.

Berdasarkan uraian di atas, maka dilakukan analisis pengaruh jarak pemasangan PVD terhadap derajat konsolidasi pada konstruksi timbunan pada proyek Reklamasi Peti Kemas Belawan Fase II secara empiris maupun dengan Plaxis 2D. 


\section{Metode Penelitian}

Perhitungan dalam analisis ini dilakukan dengan menggunakan data yang didapatkan dari Proyek Reklamasi Peti Kemas Belawan. Data yang digunakan berupa data borring log, gambar penampang timbunan, proses konstruksi, data laboratorim tanah dan data spesifikasi PVD yang digunakan pada proyek tersebut serta data monitoring yakni settlement plate sebagai pembanding dari analisis yang dilakukan.

Analisis dimulai dengan melakukan perhitungan besar penurunan yang terjadi pada proses preloading dengan teori konsolidasi one dimensional. Selanjutnya dilakukan perhitungan derajat konsolidasi dengan menghitung waktu yang dilakukan untuk mencapai derajat konsolidasi 90\% baik tanpa PVD maupun dengan PVD.

Perhitungan derajat konsolidasi dengan PVD dilakukan pada pemasangan PVD dengan jarak 1,1 m, 1,3 m dan 1,5 m dengan pola segitiga baik tanpa memperhitungkan pengaruh smear zone maupun dengan pengaruh smear zone (Von Niessen \& Gindrat, 2011).

Analisis terakhir yang dilakukan adalah dengan pemodelan Plaxis $2 D$. Hasil dari perhitungan yang dilakukan yang kemudian akan dianalisis untuk mendapatkan kesimpulan yang menjadi tujuan dari penelitian ini.

\section{Hasil dan Pembahasan}

\section{Perhitungan Penurunan Konsolidasi Primer secara Empiris}

Analisis awal yang dilakukan adalah menghitung besarnya penurunan konsolidasi primer yang terjadi saat dengan beban preloading yang berikan menggunakan persamaan $S=\frac{C_{c} \cdot H}{1+e_{0}} \log \left(\frac{P_{0}+\Delta P}{P_{0}}\right)$ sehingga diperoleh nilai penurunan seperti tertera pada Tabel 1 .

\section{Tabel 1}

Perhitungan Penurunan Konsolidasi Primer

\begin{tabular}{|c|c|c|c|c|c|c|}
\hline Lapisan & $\begin{array}{c}\text { Elevasi tanah lunak } \\
\text { setiap lapisan }\end{array}$ & $\begin{array}{c}\text { Ketebalan } \\
(\mathbf{H})(\mathbf{m})\end{array}$ & $\begin{array}{c}\text { Kedalaman } \\
\text { efektif }(Z)(m)\end{array}$ & $\begin{array}{c}P_{0} \\
\left(k N / m^{2}\right)\end{array}$ & $\begin{array}{c}\Delta \mathbf{P} \\
\left(\mathbf{k N} / \mathbf{m}^{2}\right)\end{array}$ & $\mathbf{S}_{\mathbf{p}}(\mathbf{m})$ \\
\hline 1 & $0-4,7$ & 4,7 & 2,35 & 19,27 & 100,1 & 0,000 \\
\hline 2 & $4,7-8,8$ & 4,1 & 2,05 & 47,15 & 100,1 & 0,400 \\
\hline 3 & $8,8-10,5$ & 1,7 & 0,85 & 62,73 & 100,1 & 0,000 \\
\hline 4 & $10,5-14,6$ & 4,1 & 2,05 & 83,435 & 100,1 & 0,207 \\
\hline 5 & $14,6-16,6$ & 2 & 1 & 103,37 & 100,1 & 0,096 \\
\hline 6 & $16,6-19,8$ & 3,2 & 1,6 & 119,49 & 100,1 & 0,139 \\
\hline 7 & $19,8-30$ & 10,2 & 5,1 & 161,03 & 100,1 & 0,351 \\
\hline 8 & $30-37,2$ & 7,2 & 3,6 & 216,77 & 100,1 & 0,195 \\
\hline 9 & $37,2-43$ & 5,8 & 2,9 & 261,77 & 100,1 & 0,125 \\
\hline 10 & $43-46,9$ & 3,9 & 1,95 & 300,59 & 100,1 & 0,048 \\
\hline 11 & $46,9-48,5$ & 1,6 & 0,8 & 327,49 & 100,1 & 0,019 \\
\hline 12 & $48,5-52$ & 3,5 & 1,75 & 357,8 & 100,1 & 0,037 \\
\hline 13 & $52-53,96$ & 1,96 & 0,98 & 391,106 & 100,1 & 0,019 \\
\hline \multicolumn{6}{|c|}{ Total Penurunan } & 1,637 \\
\hline
\end{tabular}

Sumber: Hasil perhitungan 
Berdasarkan Tabel 1, besar penurunan akibat konsolidasi primer yang diperoleh adalah sebesar 1,637 meter.

\section{Perhitungan Derajat Konsolidasi tanpa Menggunakan PVD}

Perhitungan derajat konsolidasi dengan asumsi tidak menggunakan PVD dilakukan dengan rumus yang diberikan oleh (Terzaghi, 1925). Adapun hasil perhitungan adalah sebagai berikut.

$$
\begin{gathered}
U_{v}=\frac{\sqrt{\frac{4 \cdot T_{v}}{\pi}}}{\left(1+\left(\frac{4 \cdot T_{v}}{\pi}\right)^{2,8}\right)^{0,179}} \\
T_{v}=\frac{C_{v} \cdot t}{H^{2}}
\end{gathered}
$$

Di mana: $\mathrm{Tv}=$ faktor waktu, $\mathrm{Cv}=$ koefisien konsolidasi arah vertikal $(\mathrm{cm} 2 / \mathrm{s}), \mathrm{t}$ = waktu yang dibutuhkan untuk mencapai derajat konsolidasi (s), $\mathrm{H}=$ panjang maksimum lintasan drainase $(\mathrm{cm})$.

Untuk tanah yang berlapis-lapis dengan ketebalan yang berbeda-beda, harga $C_{v}$ gabungan dapat dihitung dengan Persamaan berikut.

$$
C_{v \text { gabungan }}=\frac{\left(H_{1}+H_{2}+\cdots+H_{n}\right)^{2}}{\left(\frac{H_{1}}{\sqrt{c_{v 1}}}+\frac{H_{2}}{\sqrt{c_{v 2}}}+\cdots+\frac{H_{3}}{\sqrt{c_{v 3}}}\right)^{2}}
$$

Dengan menggunakan persamaan-persamaan di atas diperoleh nilai sebagai berikut:

$$
\begin{aligned}
& C_{v \text { gabungan }} \\
& (4,1+4,1+2+3,2+10,2+7,2+5,8+3,9+1,6+3,5+1,96)^{2} \\
& =\frac{4,1}{\left(\frac{4,1}{\sqrt{0,0001}}+\frac{2}{\sqrt{0,0002}}+\frac{2}{\sqrt{0,00025}}+\frac{3,2}{\sqrt{0,00045}}+\frac{10,2}{\sqrt{0,00045}}+\frac{7,2}{\sqrt{0,00045}}+\frac{5,8}{\sqrt{0,0005}}+\frac{3,9}{\sqrt{0,0006}}+\frac{1,6}{\sqrt{0,00075}}+\frac{3,5}{\sqrt{0,0009}}+\frac{19,6}{\sqrt{0,0009}}\right)^{2}} \\
& C_{v \text { gabungan }}=0,0032 \mathrm{~m}^{2} / \text { hari } \\
& H=\frac{47,56}{2}=23,78 \mathrm{~m} \\
& T_{v}=\frac{0,0032 \times 1}{23,78^{2}}=5,66 \times 10^{-6} \\
& U_{v}=\frac{\sqrt{\frac{4 \times 5,66 \times 10^{-6}}{3,14}}}{\left(1+\left(\frac{4 \times 5,66 \times 10^{-6}}{3,14}\right)^{2,8}\right)^{0,179}}=2,685 \times 10^{-3} \\
& t=\frac{0,848 \times 23,78^{2}}{0,0032}=149854,426 \text { hari }=410,56 \text { tahun } \approx 411 \text { tahun }
\end{aligned}
$$


Hasil perhtiungan derajat konsolidasi tanpa menggunakan PVD diberikan pada Tabel 2.

Tabel 2

Hasil Analisis Derajat Konsolidasi Arah Vertikal Tanpa Menggunakan PVD

\begin{tabular}{cccc}
\hline $\mathbf{U}_{\mathbf{v}} \mathbf{( \% )}$ & $\mathbf{T}_{\mathbf{v}}$ & $\mathbf{t}(\mathbf{h a r i})$ & $\mathbf{S}_{\mathbf{p}}(\mathbf{m})$ \\
\hline 0 & 0 & 0 & 0 \\
\hline $10 \%$ & 0,008 & 1414 & 0,000594 \\
\hline $20 \%$ & 0,031 & 5478 & 0,005939 \\
\hline $30 \%$ & 0,071 & 12547 & 0,029695 \\
\hline $40 \%$ & 0,126 & 22266 & 0,098984 \\
\hline $50 \%$ & 0,196 & 34636 & 0,24746 \\
\hline $60 \%$ & 0,283 & 50010 & 0,49492 \\
\hline $70 \%$ & 0,403 & 71216 & 0,824866 \\
\hline $80 \%$ & 0,567 & 100197 & 1,17838 \\
\hline $90 \%$ & 0,848 & 149854 & 1,472975 \\
\hline $100 \%$ & - & - & 1,637 \\
\hline \multicolumn{4}{c}{}
\end{tabular}

Sumber: hasil perhitungan

\section{Perhitungan Derajat Konsolidasi pada Timbunan Menggunakan PVD tanpa Memperhitungkan Efek Smear Zone}

Perhitungan derajat konsolidasi timbunan yang menggunakan PVD tanpa memperhitungkan efek smear zone dilakukan dengan menggunakan persamaanpersamaan berikut.

$$
C_{h}=(1-2) * C_{v}
$$

Derajat konsolidasi arah radial, Ur dapat ditentukan dengan metode Barron, 1948 menggunakan persamaan sebagai berikut:

$$
\begin{array}{r}
U_{r}=1-e^{\frac{-8 T_{r}}{F}} \\
T_{r}=\frac{C_{v} \cdot t}{D_{e}^{2}}
\end{array}
$$

Di mana $\operatorname{Tr}=$ faktor waktu arah radial, De adalah diameter ekuivalen vertical drain (setelah penampang diubah menjadi bentuk lingkaran) dan $\mathrm{F}$ adalah faktor hambatan diakibatkan jarak antar PVD.

$$
\begin{gathered}
n=\frac{r_{e}}{r_{w}} \\
k=\frac{k_{h 0}}{k_{h s}} \approx 2-4 \\
s=\frac{d_{s}}{d_{w}}
\end{gathered}
$$


Adapun keterangan persamaan adalah: $r_{e}$ jari-jari ekuivalen pemasangan PVD, $r_{w}=$ jari-jari PVD, $\mathrm{d}_{\mathrm{s}}=$ diameter smear zone, $d_{w}=$ diameter PVD, $k_{h 0}=$ koefisien permeabilitas horizontal tanah eksisting, $k_{h s}=$ koefisien permeabilitas horizontal tanah akibat smear zone.

Derajat konsolidasi tanah (U) merupakan besarnya perbandingan penurunan tanah pada waktu tertentu dengan penurunan total. Persamaan derajat konsolidasi pada tanah yang distabilisasi dengan menggunakan sistem PVD menurut (Carillo, 1942) adalah sebagai berikut:

$$
U=1-\left(1-U_{v}\right)\left(1-U_{r}\right)
$$

Besarnya derajat konsolidasi yang dihasilkan untuk pemasangan PVD dengan jarak 1,1 m, 1,3 $\mathrm{m}$ dan 1,5 $\mathrm{m}$ dengan pola pemasangan segitiga disajikan pada Tabel 3, Tabel 4, dan Tabel 5.

\section{Tabel 3}

Derajat Konsolidasi yang Terjadi pada Pemasangan PVD Jarak 1,1 M Pola Segitiga Tanpa Efek Smear Zone

\begin{tabular}{ccccccc}
\hline t (hari) & $\mathbf{T}_{\mathbf{v}}$ & $\mathbf{U}_{\mathbf{v}}(\boldsymbol{\%})$ & $\mathbf{T}_{\mathbf{r}}$ & $\mathbf{U}_{\mathbf{r}}(\boldsymbol{\%})$ & $\mathbf{U}(\boldsymbol{\%})$ & $\mathbf{S}_{\mathbf{p}}(\mathbf{m})$ \\
\hline $\mathbf{1}$ & $3,59843 \mathrm{E}-06$ & 0,002141 & 0,007283 & 0,027165 & 0,029248 & 0,047869 \\
\hline $\mathbf{2}$ & $7,19687 \mathrm{E}-06$ & 0,003028 & 0,014566 & 0,053593 & 0,056458 & 0,092402 \\
$\mathbf{3}$ & $1,07953 \mathrm{E}-05$ & 0,003708 & 0,021849 & 0,079302 & 0,082716 & 0,135377 \\
\hline $\mathbf{1 0}$ & $3,59843 \mathrm{E}-05$ & 0,006771 & 0,07283 & 0,24074 & 0,245881 & 0,402418 \\
\hline $\mathbf{8 0}$ & 0,000287875 & 0,01915 & 0,582644 & 0,889561 & 0,891676 & 1,459351 \\
\hline 85 & $\mathbf{0 , 0 0 0 3 0 5 8 6 7}$ & $\mathbf{0 , 0 1 9 7 3 9}$ & $\mathbf{0 , 6 1 9 0 5 9}$ & $\mathbf{0 , 9 0 3 7 6 8}$ & $\mathbf{0 , 9 0 5 6 6 8}$ & $\mathbf{1 , 4 8 2 2 5 1}$ \\
\hline $\mathbf{1 0 0}$ & 0,000359843 & 0,02141 & 0,728305 & 0,936335 & 0,937698 & 1,534673 \\
\hline $\mathbf{1 2 0}$ & 0,000431812 & 0,023454 & 0,873966 & 0,963298 & 0,964159 & 1,577981 \\
\hline
\end{tabular}

Sumber: hasil perhitungan

\section{Tabel 4}

Derajat Konsolidasi yang Terjadi pada Pemasangan PVD Jarak 1,3 M Pola Segitiga Tanpa Efek Smear Zone

\begin{tabular}{ccccccc}
\hline t (hari) & $\mathbf{T}_{\mathbf{v}}$ & $\mathbf{U}_{\mathbf{v}}(\boldsymbol{\%})$ & $\mathbf{T}_{\mathbf{r}}$ & $\mathbf{U}_{\mathbf{r}}(\boldsymbol{\%})$ & $\mathbf{U}(\boldsymbol{\%})$ & $\mathbf{S}_{\mathbf{p}}(\mathbf{m})$ \\
\hline $\mathbf{1}$ & $3,59843 \mathrm{E}-06$ & 0,002141 & 0,005214 & 0,01811 & 0,020212 & 0,03308 \\
\hline $\mathbf{2}$ & $7,19687 \mathrm{E}-06$ & 0,003028 & 0,010429 & 0,035891 & 0,038811 & 0,063519 \\
\hline $\mathbf{3}$ & $1,07953 \mathrm{E}-05$ & 0,003708 & 0,015643 & 0,053351 & 0,056862 & 0,093062 \\
\hline $\mathbf{1 0}$ & $3,59843 \mathrm{E}-05$ & 0,006771 & 0,052145 & 0,167029 & 0,172669 & 0,282596 \\
\hline $\mathbf{1 0 0}$ & 0,000359843 & 0,02141 & 0,521449 & 0,839196 & 0,842638 & 1,379095 \\
\hline $\mathbf{1 2 0}$ & 0,000431812 & 0,023454 & 0,625739 & 0,888427 & 0,891044 & 1,458318 \\
\hline 130 & $\mathbf{0 , 0 0 0 4 6 7 7 9 6}$ & $\mathbf{0 , 0 2 4 4 1 1}$ & $\mathbf{0 , 6 7 7 8 8 4}$ & $\mathbf{0 , 9 0 7 0 6 3}$ & $\mathbf{0 , 9 0 9 3 3 2}$ & $\mathbf{1 , 4 8 8 2 4 8}$ \\
\hline $\mathbf{1 5 0}$ & 0,000539765 & 0,026222 & 0,782173 & 0,935517 & 0,937208 & 1,533871 \\
\hline $\mathbf{2 5 0}$ & 0,000899608 & 0,033853 & 1,303622 & 0,989631 & 0,989982 & 1,620243 \\
\hline
\end{tabular}

Sumber: hasil perhitungan 


\section{Tabel 5}

Derajat Konsolidasi yang Terjadi pada Pemasangan PVD Jarak

1,5 M Pola Segitiga Tanpa Efek Smear Zone

\begin{tabular}{ccccccc}
\hline $\mathbf{t}$ (hari) & $\mathbf{T}_{\mathbf{v}}$ & $\mathbf{U}_{\mathbf{v}}(\boldsymbol{\%})$ & $\mathbf{T}_{\mathbf{r}}$ & $\mathbf{U}_{\mathbf{r}}(\boldsymbol{\%})$ & $\mathbf{U}(\boldsymbol{\%})$ & $\mathbf{S}_{\mathbf{p}}(\mathbf{m})$ \\
\hline $\mathbf{1}$ & $3,59843 \mathrm{E}-06$ & 0,002141 & 0,003917 & 0,012834 & 0,014948 & 0,024464 \\
\hline $\mathbf{2}$ & $7,19687 \mathrm{E}-06$ & 0,003028 & 0,007833 & 0,025504 & 0,028454 & 0,046569 \\
\hline $\mathbf{3}$ & $1,07953 \mathrm{E}-05$ & 0,003708 & 0,01175 & 0,03801 & 0,041578 & 0,068048 \\
\hline $\mathbf{7 0}$ & 0,00025189 & 0,017913 & 0,274166 & 0,595137 & 0,60239 & 0,985894 \\
\hline $\mathbf{8 0}$ & 0,000287875 & 0,01915 & 0,313333 & 0,644198 & 0,651011 & 1,06547 \\
\hline $\mathbf{1 7 0}$ & 0,000611734 & 0,027916 & 0,665832 & 0,888745 & 0,891851 & 1,459638 \\
\hline 180 & $\mathbf{0 , 0 0 0 6 4 7 7 1 8}$ & $\mathbf{0 , 0 2 8 7 2 5}$ & $\mathbf{0 , 7 0 4 9 9 9}$ & $\mathbf{0 , 9 0 2 2 2 7}$ & $\mathbf{0 , 9 0 5 0 3 5}$ & $\mathbf{1 , 4 8 1 2 1 6}$ \\
\hline $\mathbf{2 0 0}$ & 0,000719687 & 0,030279 & 0,783332 & 0,924487 & 0,926773 & 1,516793 \\
\hline
\end{tabular}

Sumber: hasil perhitungan

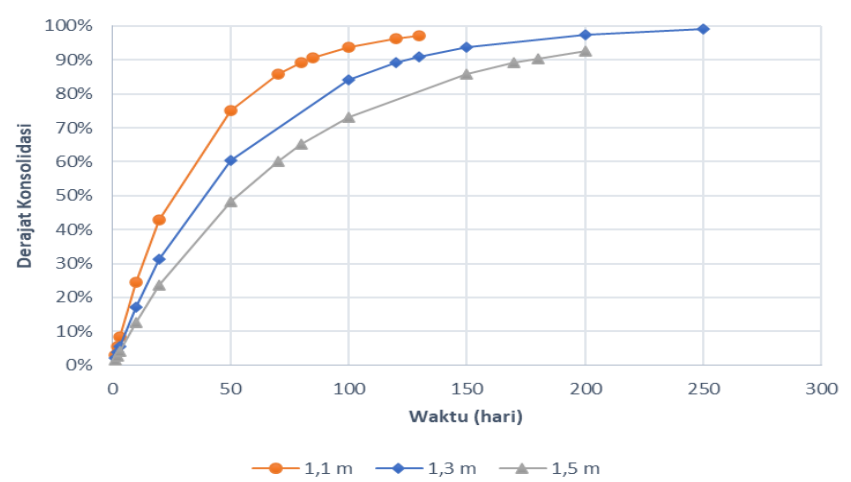

Gambar 1

Grafik Hubungan Derajat Konsolidasi dan Waktu pada Pemasangan PVD Pola Segitiga Tanpa Memperhitungkan Efek Smear Zone

\section{Perhitungan Derajat Konsolidasi pada Timbunan Menggunakan PVD dengan} Memperhitungkan Efek Smear Zone

Persamaan yang digunakan pada perhitungan ini adalah sama dengan perhitungan tanpa efek smear zone sebelumnya hanya hanya terjadi perubahan pada faktor hambatan $\mathrm{F}$ yang akan digunakan pada perhitungan.

Nilai dari faktor hambatan, $\mathrm{F}$ dengan asumsi tidak ada daerah yang terganggu akibat pemasangan PVD dikemukakan oleh (Kjellman, 1949). Selanjutnya (Hansbo, 1979) mengembangkan persamaan untuk menentukan faktor hambatan dengan asumsi perubahan koefisien permeabilitas pada daerah smear zone konstan. Adapun persamaan tersebut adalah sebagai berikut.

$$
\begin{gathered}
F=\ln (n)-0,75 \\
F=\ln \left(\frac{n}{s}\right)-0,75+k \cdot \ln (s)
\end{gathered}
$$


Berdasarkan hasil perhitungan didapatkan derajat konsolidasi yang terjadi pada timbunan yang menggunakan PVD dengan jarak pemasangan 1,1 m, 1,3 m dan 1,5 m dengan pola segitiga dengan memperhitungkan efek smear zone disajikan pada tabel.

\section{Tabel 6}

Derajat Konsolidasi yang Terjadi pada Pemasangan PVD Jarak 1,1 M Pola Segitiga Efek Smear Zone Konstan

\begin{tabular}{ccccccc}
\hline t (hari) & $\mathbf{T}_{\mathbf{v}}$ & $\mathbf{U}_{\mathbf{v}}(\boldsymbol{\%})$ & $\mathbf{T}_{\mathbf{r}}$ & $\mathbf{U}_{\mathbf{r}}(\boldsymbol{\%})$ & $\mathbf{U}(\boldsymbol{\%})$ & $\mathbf{S}_{\mathbf{p}}(\mathbf{m})$ \\
\hline $\mathbf{1}$ & $3,59843 \mathrm{E}-06$ & 0,002141 & 0,007283 & 0,016857 & 0,018962 & 0,031035 \\
$\mathbf{2}$ & $7,19687 \mathrm{E}-06$ & 0,003028 & 0,014566 & 0,033431 & 0,036357 & 0,059504 \\
\hline $\mathbf{3}$ & $1,07953 \mathrm{E}-05$ & 0,003708 & 0,021849 & 0,049725 & 0,053249 & 0,087149 \\
\hline $\mathbf{1 0 0}$ & 0,000359843 & 0,02141 & 0,728305 & 0,817338 & 0,821249 & 1,344088 \\
\hline $\mathbf{1 2 0}$ & 0,000431812 & 0,023454 & 0,873966 & 0,86999 & 0,873039 & 1,42885 \\
\hline 140 & $\mathbf{0 , 0 0 0 5 0 3 7 8 1}$ & $\mathbf{0 , 0 2 5 3 3 3}$ & $\mathbf{1 , 0 1 9 6 2 7}$ & $\mathbf{0 , 9 0 7 4 6 5}$ & $\mathbf{0 , 9 0 9 8 0 9}$ & $\mathbf{1 , 4 8 9 0 2 9}$ \\
\hline $\mathbf{1 5 0}$ & 0,000539765 & 0,026222 & 1,092457 & 0,921932 & 0,923979 & 1,51222 \\
\hline
\end{tabular}

Sumber: hasil perhitungan

Tabel 7

Derajat Konsolidasi yang Terjadi pada Pemasangan PVD Jarak 1,3 M Pola Segitiga Efek Smear Zone Konstan

\begin{tabular}{ccccccc}
\hline t (hari) & $\mathbf{T}_{\mathbf{v}}$ & $\mathbf{U}_{\mathbf{v}}(\boldsymbol{\%})$ & $\mathbf{T}_{\mathbf{r}}$ & $\mathbf{U}_{\mathbf{r}}(\boldsymbol{\%})$ & $\mathbf{U}(\boldsymbol{\%})$ & $\mathbf{S}_{\mathbf{p}}(\mathbf{m})$ \\
\hline $\mathbf{1}$ & $3,59843 \mathrm{E}-06$ & 0,002141 & 0,005214 & 0,01154 & 0,013656 & 0,02235 \\
\hline $\mathbf{2}$ & $7,19687 \mathrm{E}-06$ & 0,003028 & 0,010429 & 0,022946 & 0,025904 & 0,042396 \\
$\mathbf{3}$ & $1,07953 \mathrm{E}-05$ & 0,003708 & 0,015643 & 0,034221 & 0,037802 & 0,061869 \\
\hline $\mathbf{1 5 0}$ & 0,000539765 & 0,026222 & 0,782173 & 0,824655 & 0,829253 & 1,357188 \\
\hline 200 & $\mathbf{0 , 0 0 0 7 1 9 6 8 7}$ & $\mathbf{0 , 0 3 0 2 7 9}$ & $\mathbf{1 , 0 4 2 8 9 8}$ & $\mathbf{0 , 9 0 1 8 5 7}$ & $\mathbf{0 , 9 0 4 8 2 9}$ & $\mathbf{1 , 4 8 0 8 7 9}$ \\
\hline $\mathbf{2 5 0}$ & 0,000899608 & 0,033853 & 1,303622 & 0,945068 & 0,946928 & 1,549779 \\
\hline
\end{tabular}

Sumber: hasil perhitungan

\section{Tabel 8}

Derajat Konsolidasi yang Terjadi pada Pemasangan PVD Jarak 1,5 M Pola Segitiga Efek Smear Zone Konstan

\begin{tabular}{ccccccc}
\hline t (hari) & $\mathbf{T}_{\mathbf{v}}$ & $\mathbf{U}_{\mathbf{v}}(\boldsymbol{\%})$ & $\mathbf{T}_{\mathbf{r}}$ & $\mathbf{U}_{\mathbf{r}}(\boldsymbol{\%})$ & $\mathbf{U}(\boldsymbol{\%})$ & $\mathbf{S}_{\mathbf{p}}(\mathbf{m})$ \\
\hline $\mathbf{1}$ & $3,59843 \mathrm{E}-06$ & 0,002141 & 0,003917 & 0,008349 & 0,010472 & 0,017139 \\
\hline $\mathbf{2}$ & $7,19687 \mathrm{E}-06$ & 0,003028 & 0,007833 & 0,016628 & 0,019606 & 0,032088 \\
\hline $\mathbf{3}$ & $1,07953 \mathrm{E}-05$ & 0,003708 & 0,01175 & 0,024839 & 0,028455 & 0,04657 \\
\hline $\mathbf{1 0 0}$ & 0,000359843 & 0,02141 & 0,391666 & 0,567602 & 0,57686 & 0,944111 \\
\hline $\mathbf{2 5 0}$ & 0,000899608 & 0,033853 & 0,979165 & 0,877055 & 0,881217 & 1,442235 \\
\hline 280 & $\mathbf{0 , 0 0 1 0 0 7 5 6 1}$ & $\mathbf{0 , 0 3 5 8 2 6}$ & $\mathbf{1 , 0 9 6 6 6 5}$ & $\mathbf{0 , 9 0 4 3 9 6}$ & $\mathbf{0 , 9 0 7 8 2 1}$ & $\mathbf{1 , 4 8 5 7 7 6}$ \\
\hline $\mathbf{3 0 0}$ & 0,00107953 & 0,037084 & 1,174998 & 0,919155 & 0,922153 & 1,509232 \\
\hline
\end{tabular}

Sumber: hasil perhitungan

\section{Perhitungan Konsolidasi dengan Plaxis $2 D$}

Analisis dengan Plaxis $2 D$ dilakukan dengan memodelkan konstruksi timbunan di lapangan ke dalam program Plaxis $2 D$. Pada analisis ini digunakan pemodelan plane strain. Adapun pemodelan yang dilakukan terlihat pada gambar 2. 
Selanjutnya dilakukan input parameter material tanah dan PVD kedalam program Plaxis. Parameter ini didapatkan dari data laboratorium hasil penyelidikan tanah sedangkan data PVD didapatkan dari laporan spesifikasi teknis pelaksana proyek.

Setelah melakukan input material selanjutnya dilakukan pembagian elemen (generate mesh) untuk membagi konstruksi timbunan menjadi elemen-elemen yang lebih kecil.

Tahapan selanjutya adalah memasukkan tahapan konstruksi berupa proses tahapan timbunan di lapangan kedalam Plaxis $2 D$ atau sering disebut stage construction. Adapun akhir dari analisis adalah melakukan proses perhitungan (calculate).

Berdasarkan hasil perhitungan, besar penurunan yang terjadi pada konstruksi timbunan yang menggunakan PVD tanpa memperhitungkan efek smear zone adalah 2,28 meter (gambar 2) dan besar penurunan hingga tahap pemasangan settlement plate di lapangan adalah $0,52 \mathrm{~m}$ (gambar 3). Maka besar penurunan yang sebenarnya adalah 1,76 meter. Sedangkan untuk analisis dengan memperhitungkan efek smear zone besar penurunan yang diperoleh adalah 1,484 $\mathrm{m}$. Besar penurunan dari data settlement plate di lapangan diperoleh 1,593 meter.

Hubungan waktu dan penurunan konsolidasi yang dihasilkan dari analisis Plaxis 2D disajikan pada Gambar 4.

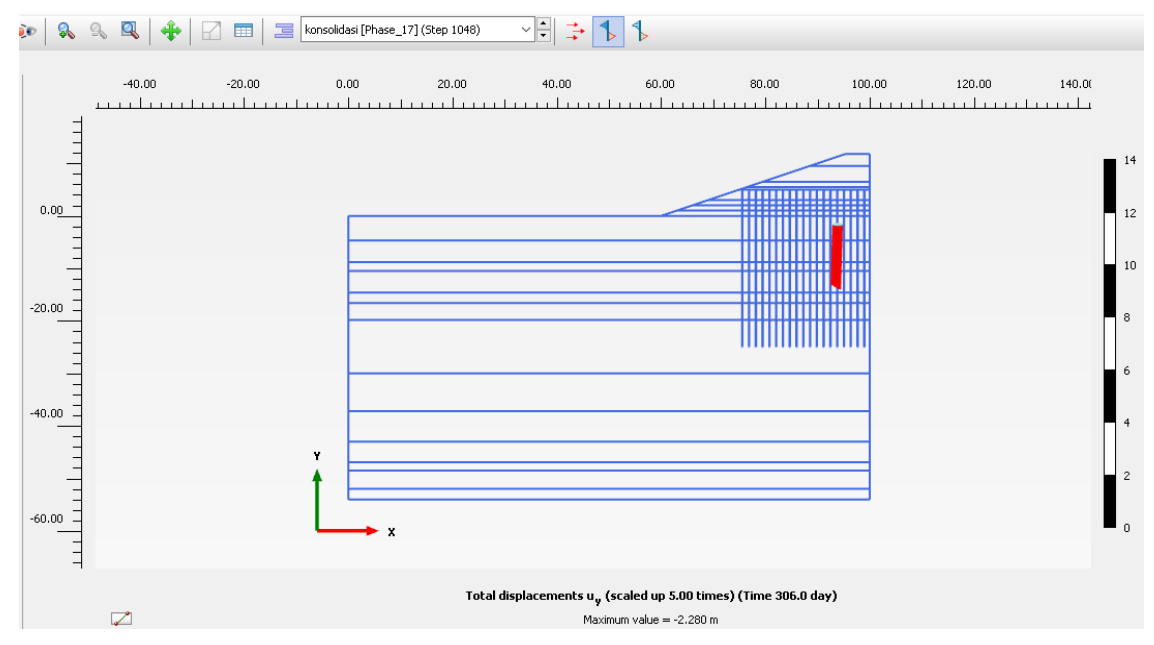

Gambar 2

Besar Penurunan yang Terjadi dari Hasil Pemodelan Plaxis 2D Tanpa Efek Smear Zone pada Tahap Akhir Konstruksi adalah 2,28 M 


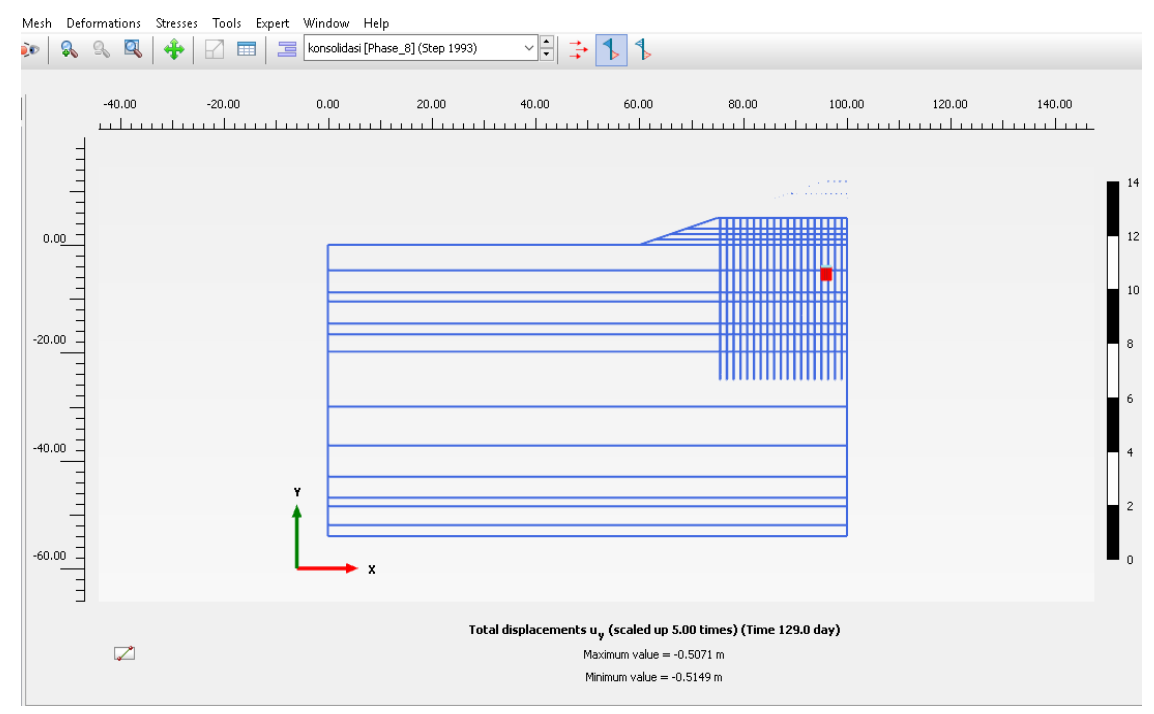

Gambar 3

\section{Besar Penurunan yang Terjadi sampai Tahap Pemasangan Settlement Plate} adalah $0,52 \mathrm{M}$

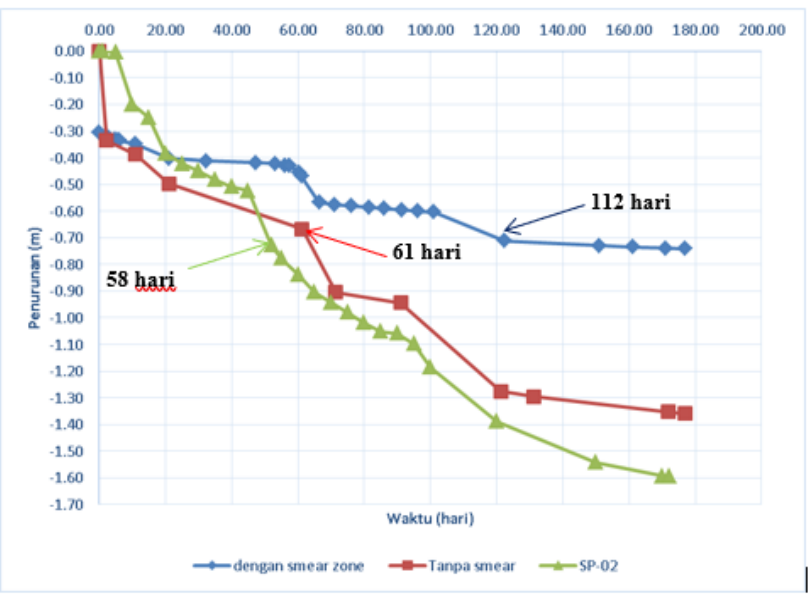

Gambar 4

Grafik Hubungan antara Penurunan dan Waktu Konsolidasi

\section{Data hasil Monitoring di Lapangan}

Monitoring di lapangan dilakukan dengan menggunakan alat settlement plate. Pencatatan besar penurunan yang terjadi dilakukan setiap hari. Berdasarkan data Settlement Plate-02 pada proyek tersebut, besar penurunan yang terjadi pada saat proses konsolidasi adalah 1,593 $\mathrm{m}$. Nilai ini yang nantinya akan menjadi pembanding bagi analisis yang telah dilakukan.

\section{Kesimpulan}

Berdasarkan hasil analisis yang telah dilakukan dapat disimpulkan bahwa besar penurunan konsolidasi secara analitis pada kasus ini memberikan nilai yang lebih mendekati kondisi di lapangan daripada analisis menggunakan Plaxis $2 D$ dimana perbedaan hasil perhitungan penurunan secara analitis terhadap kondisi lapangan hanya 2,76\%. Sedangkan hasil pemodelan Plaxis $2 D$ tanpa efek smear zone memberikan hasil 
Daniel Anderson Munthe, Roesyanto dan Rudi Iskandar

yang berbeda sebesar $10,48 \%$ dan dengan efek smear zone sebesar $6,84 \%$ terhadap kondisi di lapangan.

Pemasangan PVD pada jarak 1,1 meter menghasilkan waktu konsolidasi yang lebih sedikit daripada jarak 1,3 meter dan 1,5 meter sehingga semakin dekat jarak PVD waktu konsolidasi yang terjadi akan semakin cepat.

Untuk analisis Plaxis 2D, pemodelan dengan efek smear zone memberikan waktu yang lebih lama untuk mencapai derajat konsolidasi daripada pemodelan tanpa memperhitungkan efek smear zone. 


\section{BIBLIOGRAFI}

Adnan, U. A. (2014). Pengaruh Jarak Dan Pola Pre-Fabricated Vertical Drain (Pvd) Pada Konstruksi Timbunan Reklamasi Di Pelabuhan Panasahan Carocok Painan. Universitas Kristen Maranatha.

Ady Noegroho, A. N. (2016). Pemanfaatan Raspberry Pi Dan Webcam Sebagai Kamera Pemantau Dan Cloud Drive Sebagai Media Penyimpanan. Sekolah Tinggi Informatika Dan Komputer Indonesia Malang.

Aradea, T. M. R. (2019). Pengaruh Jarak, Pola, Dan Koefisien Konsolidasi Horizontal Terhadap Waktu Penurunan Menggunakan Metode Prefabricated Vertical Drain. Prosiding Seminar Intelektual Muda, 1(2).

Aspara, W. A. N., \& Fitriani, E. N. (2016). Pengaruh Jarak Dan Pola Prefabricated Vertical Drain (Pvd) Pada Perbaikan Tanah Lempung Lunak= Effect Of Distance And Pattern Of Prefabricated Vertical Drain For Improvement Of Soft Clay Soil. Majalah Ilmiah Pengkajian Industri, 10(1), 41-50.

Carillo, N. (1942). Investigation On Stability Of Slopes And Foundation.

Hansbo, S. (1979). Consolidation Of Clay By Bandshaped Prefabricated Drains. Ground Engineering, 12(5).

Iskandar, R. (2018). Analisis Konsolidasi Tanah Lunak Menggunakan Preloading Dan Pvd Dengan Metode Analitis Dan Metode Elemen Hingga (Studi Kasus Proyek Jalan Bebas Hambatan Medan-Kualanamu Km 36+ 100).

Kjellman, W. (1949). Record Of The Activities At The Swedish Geotechnical Insitute 1944-1948. Swedish Geotechnical Institute, Stockholm.

Munthe, D. A. (2020). Analisis Pengaruh Jarak Dan Pola Pemasangan Pvd Terhadap Derajat Konsolidasi Pada Tanah Timbunan Reklamasi Belawan Fase Ii.

Sumiati, E., Septian, D., \& Faizah, F. (2018). Pengembangan Modul Fisika Berbasis Scientific Approach Untuk Meningkatkan Keterampilan Proses Sains Siswa. Jurnal Pendidikan Fisika Dan Keilmuan (Jpfk), 4(2), 75-88.

Susiazti, H., Widiastuti, M., \& Widayati, R. (2020). Analisis Penurunan Konsolidasi Metode Preloading Dan Prefabricated Vertical Drain (Pvd). Teknologi Sipil, 4(1), 18 .

Terzaghi, K. (1925). Principles Of Soil Mechanics, Iv-Settlement And Consolidation Of Clay. Engineering News-Record, 95(3), 874-878.

Von Niessen, K., \& Gindrat, M. (2011). Plasma Spray-Pvd: A New Thermal Spray Process To Deposit Out Of The Vapor Phase. Journal Of Thermal Spray Technology, 20(4), 736-743. 
Daniel Anderson Munthe, Roesyanto dan Rudi Iskandar

Weber, T. M., Plötze, M., Laue, J., Peschke, G., \& Springman, S. M. (2010). Smear Zone Identification And Soil Properties Around Stone Columns Constructed In-Flight In Centrifuge Model Tests. Géotechnique, 60(3), 197-206.

Widhiarto, H., Fatmawati, L. E., \& Beatrix, M. (2018). Pengaruh Pvd (Prefabricated Vertical Drain) Dalam Mempercepat Proses Konsolidasi Pada Kontruksi Taxiway Di Bandara Juanda Surabaya. Jhp17: Jurnal Hasil Penelitian, 3(02).

Yapriadi, M. C., Sumarli, I., \& Iskandar, A. (2020). Evaluasi Settlement Menggunakan Surcharge Preloading Dengan Pvd Pada Proyek Di Bandung Selatan. Jmts: Jurnal Mitra Teknik Sipil, 3(3), 911-922.

Zhang, W., Pan, Z., Xiao, H., Zheng, Z., Chen, C., \& Gao, Z. (2018). Pulsed Vacuum Drying (Pvd) Technology Improves Drying Efficiency And Quality Of Poria Cubes. Drying Technology, 36(8), 908-921. 